\title{
¿Es posible la decisión ética en el campo? Sobre la real decisión de Sophie
}

\author{
Sophie’s choice | Alan J. Pakula | 1982 \\ Yairsiño Oviedo Correa" \\ Pontificia Universidad Javeriana de Colombia
}

Recibido: 27 de enero 2016; aprobado: 12 de marzo 2016

\begin{abstract}
Resumen
La inquietante figura de los campos de concentración ha motivado el intelecto e imaginación de académicos y artistas de toda clase, quienes intentan comprender la estructura de esos espacios y las dinámicas humanas a las que dan lugar. El filósofo Giorgio Agamben ha buscado está comprensión a partir de su teorización acerca delestado de excepción, el cual le permite al soberano (el Estado) suspender el ordenamiento jurídico para facilitarle un modo de actuar extrajurídico que, sin embargo, cuenta con la validez otorgada por la fuerza que puede ejercer el Estado. En los campos la excepcionalidad es la constante, propiciando unas formas sociales y unos comportamientos que transgreden aquellas formas y maneras de actuar "normales". El film Sophie'sChoice, de Alan Pakula, al igual que la novela del mismo nombre en la que se basa, escenifica una situación que ha sido interpretada como un caso de decisión ante un dilema ético (elegir sobre la vida o la muerte de los propios hijos de la protagonista) en el campo de concentración Auschwitz-Birkenau. Ante los análisis que tratan de explicar la problemática que presentan los dilemas éticos, este escrito plantea, a partir de la teoría agambeana, que en el campo no es posible hablar de una real decisión ética, pues el orden normativo tradicional es suspendido y la capacidad de discernir moralmente bloqueada, dando lugar a un comportamiento que simplemente se adecúe al orden excepcional prevaleciente.
\end{abstract}

Palabras clave: Sophie’s Choice | Giorgio Agamben | dilemas éticos | nazismo | campos de concentración.

Is it possible an ethical decision in the concentration camp? About Sophie's choice

\begin{abstract}
The unsettling figure of concentration camps has motivated the intellect and the imagination of academics and artists of all kinds, who have tried to understand the structure of those settings, and the human dynamics they foster.Philosopher Giorgio Agamben has sought this understanding based on his theorization of the state of exception, which allows the sovereign (the State) to suspend the rule of law, so as to facilitatean extrajudicial way of acting,this being nonetheless validated by the power the State is entitled to exert. In concentration camps exceptionality is a constant factor, which encourages certain social forms and behaviours that overstep what would be the "usual" forms and ways of acting. The film Sophie's Choice by Alan Pakula, alike the novel by the same name it is based on, presents us with a scenario that has been interpreted as a matter of decision-making when faced with an ethical dilemma (choosing between life and death regarding the main character's own children) in Auschwitz-Birkenau concentration camps.In view of all the analyses that try to explain the issuesthat stem from ethical dilemmas, this paper, following the agambenean theory, argues that there is no such thing as ethical decision-making in concentration camps, given that the traditional legal order has been suspended, moral discernment has been blocked, and hence what does appearis behaviour that simply adapts itselfto the exceptional circumstances that prevail.
\end{abstract}

Keywords: Sophie’s Choice | Giorgio Agamben | Ethical dilemmas | Nazism | Concentration camps

Hace ya casi veinte años Giorgio Agamben, una vez iniciadas sus reflexiones sobre la biopolítica con el Homo Sacer I, propuso, en su ensayo titulado ¿Qué es un campo?, "considerar el campo [de concentración] no como un simple hecho histórico o una anomalía perteneciente al pasado [...], sino, en algún modo, como la matriz oculta, elnomos del espacio político en que aún vivimos." ${ }^{\text {Si nos }}$ tomamos seriamente esta consideración, tendremos que redefinir nuestra manera de pensar no sólo las categorías políticas, concernientes a nuestra vida social, sino también las categorías éticas, relativas a nuestra vida individual y su relación con el entorno. En cuanto a esto último, la ética, se debe establecer en qué medida el concepto de campo transforma, subvierte o, quizá, anula el accionar moralmente válido en situaciones en las que se debe tomar una decisión que afecta la propia vida o la de los demás².

La pregunta que direccionará la presente reflexión se puede plantear de esta manera: ¿puede tomarse una 
decisión ética en el campo? Como de lo que se trata es de utilizar la figura del campo como paradigma del actual espacio político, es decir, como un caso particular a partir del cual es posible extraer formas para comprender situaciones generales, se partirá del análisis de un film que nos pone ante los problemas éticos surgidos dentro y fuera del campo, en el momento que se señala su origen espacio-temporal. Sophie'sChoice (1982), de Alan J. Pakula, es un film de ficción con un alto contenido histórico, basado en la novela del mismo nombre publicada por el escritor norteamericano William Styron en 1976. El género de la película es drama y contó con la brillante actuación de Meryl Streep (Sophie Zawistowska), quien ganó un premio Óscar a mejor actriz por esta interpretación.

Este film nos presenta, en su momento de mayor dramatismo, la difícil "decisión" que debe tomar Sophie, en la fila de selección en el campo de concentración Auschwitz-Birkenau, con respecto a cuál de sus hijos (Jan y Ana) debe salvarse de ir a las cámaras de gas. En adelante, se busca analizar si este episodio de extremo dolor -que de seguro le valió el Óscar a Meryl Streeppuede interpretarse como una decisión ética, como muchos lo han querido ver.

Antes de entrar a este análisis, es conveniente volver al ensayo de Agamben y establecer lo que, según él, es un campo. Ya desde su Homo Sacer I, Agamben devela el campo como un orden que emerge en el estado excepción, es decir, en el no-orden de lasuspensión del régimen legal ordinario, lo cual, sin embargo, genera un orden, un orden fuera del orden, pero, a la vez, un orden ordenado en el orden. A esto es a lo que se refiere Agamben cuando habla del campo como nomos, una normalización de un estado de cosas -no inteligible como una situación normal- que permite predecir y regular el comportamiento de los individuos, en primer término, y de la sociedad, en último término. La relación entre campo y estado de excepción permite identificar la configuración de tales escenarios desde, por lo menos, el siglo XIX, y no únicamente en la Alemania, sino también en otras zonas de Europa y el mundo. Pero la paradoja y novedad del campo, inaugurada por los nazis, es que "es el espacio que se abre cuando el estado de excepción empieza a convertirse en regla", esto es, cuando la suspensión temporal del orden se vuelve permanente y paralela al "orden jurídico normal”.

Entonces, el campo es un espacio, fuera del orden jurídico normal, propiciado por el mismo Estado (denominado por Agamben como "el soberano"), que es, a la vez, el sostenedor de tal orden, pero que justamente el signo de su poder real consiste en ser capaz de suspender la ley ante una situación anormal, sin por ello suspender su potestad de decidir sobre las vidas de quienes se ubiquen en ese espacio, o, mejor dicho, extendiendo su potestad de decidir tanto sobre la vida jurídica de las personas como sobre su vida biológica. Por esto, Agamben dice: "Sólo porque los campos constituyen, en el sentido que hemos visto, un espacio de excepción, en que la ley es suspendida de forma integral, todo es verdaderamente posible en ellos." Esta figura, que no es exclusivamente geográfica, le permitió a los nazis despojar a los individuos de "cualquier condición política" o caracterización socio-jurídica, de manera que el poder del Estado pudiera ejercerse directamente sobre la vida biológica (o nuda vida, como la llama Agamben) de estos entes que ya ni siquiera podían ser llamados personas.

Así pues, nada de lo que ocurra dentro de un campo puede ser considerado un delito, pues no hay un ordenamiento jurídico que permita tipificar los actos de esa manera; se pierde todo punto de referencia distinto a lo que establezca quien ejerce el poder en nombre del soberano: un comandante, un soldado, un guardia, un médico, un técnico, un recluso, etc., cualquiera de estos podía "decidir", en el caso extremo -que era habitual-, sobre la supervivencia o la muerte de un habitante del campo. "Si todo esto es cierto -concluye Agamben-, si la esencia del campo consiste en la materialización del estado de excepción y en la consiguiente creación de un espacio para la nuda vida como tal, tendremos que admitir entonces que nos encontramos virtualmente en presencia de un campo cada vez que se crea una estructura de esta índole, con independencia de los crímenes que allí se hayan cometido y cualesquiera que sean su denominación y sus peculiaridades topográficas. ${ }^{\prime 5}$

El campo de concentración, por lo tanto, concretiza los mecanismos que dispuso el nazismo para asegurar, según ellos, la supervivencia biológica del pueblo alemán. Sí, "la supervivencia biológica”, pues, la perspectiva que une política y biología (bio-política), no sólo servía para proceder en contra de los "enemigos del Reich", sino también para tener un control pleno de la sociedad en su totalidad. ${ }^{6}$ De acuerdo a Roberto Esposito, ni siquiera puede decirse que en aquel entonces se haya instrumentalizado a la biología, sino que conscientemente se gestó una identificación entre ésta y la política; en otras palabras, se dio lugar a una "biocracia". Tales mecanismos fueron tres: 1) Normalización absoluta de la vida, que implicó el aumento del poder médico con la formulación 
y aplicación de normas sobre eutanasia y mejoramiento racial, cuyo efecto en los campos de concentración fue la participación de los médicos en las prácticas de selección que, bajo supuestos parámetros "científicos", decidían, como si se tratara de "sacerdotes de la vida y de la muerte", quien debía morir inmediatamente y quien era apto para realizar trabajos forzados. 2) Doble cierre del cuerpo, que redujo la identidad de las personas a su pura existencia biológica, a su cuerpo como evidencia de su origen racial, de modo que la distinción entre alma y cuerpo desaparece para encontrar una identificación absoluta bajo el concepto de raza. ${ }^{8} \mathrm{Y}$ 3) Supresión anticipada del nacimiento, según la cual el régimen no buscaba solamente suprimir la vida de sus enemigos, sino impedir su inicio a través de campañas masivas de esterilización y, posteriormente, eliminación de la progenie. Los campos no tenían como función finalizar la existencia de los individuos, sino negar su existencia, poner en entredicho el hecho de que alguna vez hayan existido; razón por la cual podía dárseles muerte impunemente y negárseles la muerte por propia mano. ${ }^{9}$

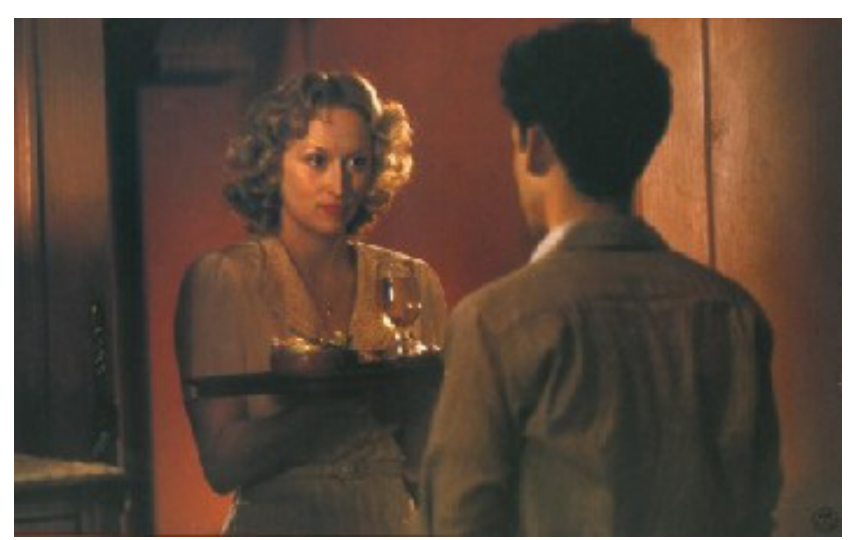

Con este marco teórico en mente, es el momento adecuado para rememorar el episodio de la "decisión" de Sophie. Aunque ya anteriormente Sophie (mujer polaca de unos 30 años, sobreviviente de los campos y residente en EE.UU. como emigrante) le había contado a Stingo (narrador de toda la historia y personaje que encarna a William Styron en su juventud) cómo había sido su llegada al campo de concentración de Auschwitz-Birkenau -cuenta que la habían atrapado contrabandeando carne para alimentar a su madre que se encontraba enferma de tuberculosis ${ }^{10}$-, sólo hasta casi el final de la película Sophie se atreve a darle detalles a Stingo del instante de la selección ${ }^{11}$. Las imágenes de la película muestran a Sophie y sus dos hijos entre los deportados de todas las procedencias, quienes eran obligados a organizarse en largas filas. Sophie y sus hijos se encontraban en la fila de quienes esperaban la selección, cuando el médico-oficial ${ }^{12}$ encargado de esta tarea se detiene al lado de Sophie y le hace insinuaciones sexuales. Posteriormente, la secuencia presenta el siguiente diálogo:

-Jemand: ¿Eres polaca?

[Sophie asiente moviendo la cabeza (está asustada)]

-Jemand: ¿ También eres una de esas comunistas asquerosas?

[Sophie lo niega moviendo la cabeza]

[El médico pierde interés y se marcha. Pero Sophie cree ver una posibilidad de salvarse y salvar a sus hijos.]

-Sophie: ¡Soy polaca! ¡Nací en Cracovia! ¡No soy judía! iMis hijos tampoco! No son judios. Son racialmente puros. Soy cristiana. Soy una católica devota. _[Con esto llama la atención del médico nuevamente.]

-Jemand: ¿No eres una comunista?

[Sophie lo niega moviendo la cabeza.]

-Eres una creyente.

-Sophie: Sí, señor. Creo en Cristo.

-Jemand: ¿̇Aí que crees en Cristo... el Redentor?

-Sophie: ;Si!

-Jemand: ¿No dijo Él... "sufran los niños pequeños para que vengan a Mi"? Puedes quedarte con uno de tus hijos.

-Sophie: ¿ Cómo dice?

-Jemand: Puedes quedarte con uno de tus hijos. El otro debe irse.

-Sophie: ¿Está diciendo que debo elegir?

-Jemand: Eres una polaca, no una Yid. Eso te da un privilegio, una elección.

-Sophie: ;No puedo elegir! ;No puedo elegir! [alza la voz]

-Jemand: Cállate.

-Sophie: ;No puedo elegir!

-Jemand: ¡Elije! ¡O enviaré a ambos para allá! ¡Haz una decisión!

-Sophie: ;No me haga elegir! ¡No puedo!

-Jemand: Enviaré a ambos para allá.

-Sophie: ;No! [Grita]

-Jemand: ;Ya basta! ;Te dije que te callaras! ;Haz una decisión!

-Sophie: ;No me haga elegir! ;No puedo!

-Jemand: Enviaré a ambos para allá.

-Sophie: ¡No puedo elegir!

-Jemand: ;Llévese a ambos niños! ¡Rápido! [Le grita a un soldado]

-Sophie: ;Llévese a mi niñita! ;Lévese a mi bebé! ;Llévese a mi niñita! 
[Es así como Sophie ve que se llevan a su hija Eva hacia el campo de exterminio, conmocionada por un hecho que no sabe cómo explicar]. ${ }^{13}$

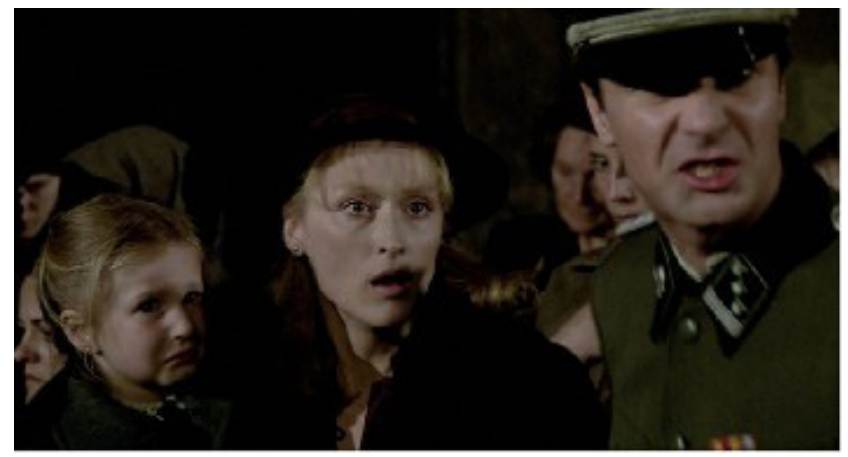

Esta secuencia, tanto del film como de la novela original, es la que ha causado debates irresueltos acerca de si la decisión de Sophie fue éticamente correcta. La politóloga Suzanne Lynn Dovi, en un artículo dedicado a analizar las decisiones éticas, presenta la elección de Sophie como un "auténtico dilema moral”, pues si deja que los dos niños mueran transgrede su obligación maternal de protegerlos bajo cualquier circunstancia, pero si elige uno de los dos se convierte en cómplice de un "esquema perverso" que pone en riesgo la vida de sus hijos, y de paso transgrede la norma que dicta que una madre no puede amar y preferir a un hijo por sobre otro (una buena madre no puede preferir la vida de uno y despreciar la de otro). ${ }^{14}$

Según esta autora, el carácter moral de la elección de Sophie se evidencia en el hecho de que, a pesar de no haber tenido la oportunidad de elegir reflexivamente, ella vive atormentada por "la culpa" de haber elegido a Eva y por las "razones que tuvo" para tal elección. El carácter dilemático de la situación lo encuentra Dovi en el hecho de que se trata de una "elección difícil”, es decir, una decisión que requiere de "nosotros elegir entre fines, propósitos, valores o bienes en conflicto que son muy importantes para nosotros". ${ }^{15}$ Los dilemas son elecciones vitales a las cuales nos vemos sometidos justamente por tener una vida compleja; por esto, "las elecciones difíciles se convierten en genuinos dilemas morales cuando un agente no puede evitar transgredir sus concepciones morales más profundas”. ${ }^{16}$ Así pues, según Dovi, un dilema moral genuino es aquel que no tiene respuesta correcta, pues, desde la visión del agente, no existe un resultado preferible en términos morales (de lo bueno y lo malo) o cualquier resultado es igualmente horrible. En esos casos la justificación moral por haber elegido una $\mathrm{u}$ otra cosa es imposible, lo cual tiene unos costos morales muy serios para el agente.
Dovi identifica tres características de la elección de Sophie: ${ }^{17}$ 1) Ningún resultado de la elección es mejor que otro; o bien lleva a la muerte de uno de los dos, o bien los dos niños mueren. 2) Participar en el proceso de elección genera una carga moral distinta a la que genera la elección de uno de los dos niños; en esto radica el horror al que se ve enfrentada Sophie. 3) Las opciones presentadas para la elección no fueron determinadas por Sophie misma, de modo que no puede decirse que cumpla un "rol activo" en la creación de las circunstancias que llevan al episodio, es decir, ella no es responsable de crear el dilema moral sobre el cual debe decidir. La inexistencia de un resultado preferible, la necesidad de aliviar las cargas morales generadas en el proceso de elección y la determinación externa de las alternativas de elección, son justamente las tres condiciones que le permiten proponer a Dovi que en estos casos es justificable utilizar un método de elección aleatorio, pues: no hay razones válidas para preferir elegir a uno u otro niño, permite que el sentimiento de culpa se reduzca debido a que no se participaría propiamente de una elección y crea una distancia entre el agente y los resultados del proceso de decisión. ${ }^{18}$

Lo anterior quiere decir que, ante una situación como la que presenta la elección de Sophie, sería conveniente "lanzar una moneda" y dejarlo a la suerte, ya que, a pesar de poder decir que Sophie se encontraba ante un dilema moral real -decidiendo entre dos valores inconmensurables-, la elección al azar puede tranquilizar al agente que se ve forzado a elegir, de modo que no se genere el sentimiento de haber cometido un crimen por participar en el esquema perverso impuesto por el médico nazi, y a pesar de no poder evadir el sentimiento de haber transgredido las obligaciones morales que dicta el instinto maternal. Visto así, parece ser que Dovi tiene razones suficientes para concluir que el método aleatorio es el que debió usar Sophie en su elección, pero lo que muestra el film -y la novela en mayor medida- es que no fue así, puesto que Sophie tenía en mente datos muy precisos que, creía ella, le permitirían argumentar para salvarse y salvar a los niños, o por lo menos para sólo salvarlos a ellos.

Antes del nefasto episodio de la elección hay una escena en la que Sophie, tratando de ganar credibilidad con Stingo -pues este había descubierto que ella no había sido lo suficientemente sincera con él-, le habla acerca de su estancia en Varsovia antes de su envío al campo. Allí, cuenta Sophie, vivía con un una mujer (Wanda) perteneciente a la resistencia y con su hermano, que en ese momento era su amante. Wanda es la primera en hablarle del programa de germanización “Lebensborn" y le muestra fotos de ni- 
ños que habían sido raptados (por tener rasgos arios) para entrar al programa y ser asimilados por familias alemanas, pero que, por no cumplir con las expectativas, eran rechazados y, luego, aniquilados. El objetivo de Wanda era conseguir que Sophie tradujera unos documentos para no permitir que eso siguiera sucediendo en la zona, pero Sophie se niega arguyendo que no puede poner en peligro a sus hijos. Dos semanas después mataron a su amante y a ellas las llevaron al campo. ${ }^{19}$ Aunque el film no lo muestra, la novela muestra cómo, antes de su llegada al campo, Sophie consideraba que su hijo Jan, al igual que ella, era más cercano a los estándares germánicos, mientras que Eva había sido educada de una forma menos germanizante. Esto quiere decir que, con anterioridad a la detención e internamiento, Sophie era perfectamente consciente, primero, del plan de "limpieza" racial de los nazis, y, segundo, de que su hijo Jan tenía los rasgos y cualidades necesarias para ingresar al Lebensborn. Más adelante, cuando cumple funciones secretariales para el Reichsführer Rudolf Höss (comandante general de Auschwitz-Birkenau), Sophie recuerda que le mencionó ese programa de germanización a Höss para proponerle una "manera legal" de liberar a Jan del campo y salvarlo de la muerte.

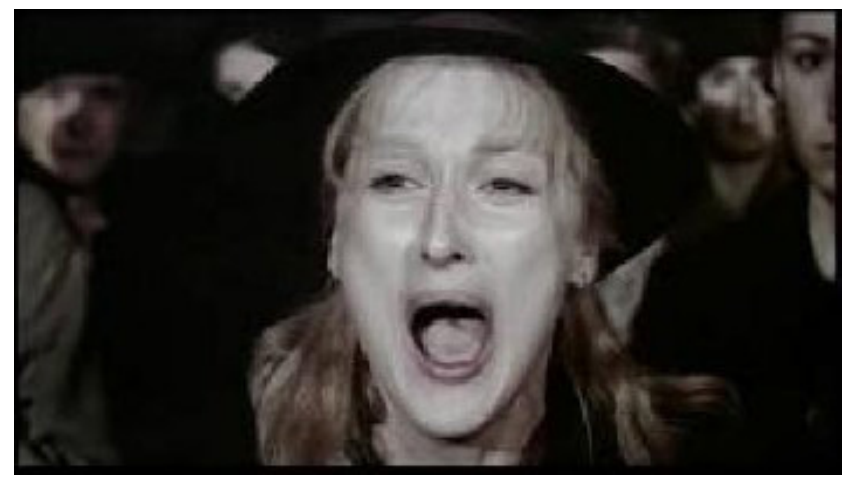

¿Esto significa que Sophie sí es responsable, éticamente hablando, de la elección hecha en el campo? Suzanne Dovi, sin hacer mención al apartado anterior, responde: "me inclino hacia la posición de que Sophie no está sujeta a ningún requerimiento moral, ya sea al elegir o no, porque no tiene sentido responder a la pregunta de qué debería hacer moralmente Sophie. Dado que ella encara una decisión horrenda bajo condiciones horrendas, sería cruel y desacertado pedir a Sophie elegir o no elegir" ${ }^{20} \mathrm{En}$ otras palabras, lo que quiere decir Dovi es que el estatus moral de Sophie es "indeterminado", pues ninguna de las decisiones que pueda tomar puede ser juzgada éticamente. De aquí extrae su propuesta del método de elección aleatoria, ya que no hay ninguna racionalidad práctica que nos permita establecer cuál es el camino más adecuado en este tipo de situaciones. Con esto pretende responder a aquellos que consideran que el gran error de Sophie fue no haberse resistido activamente a su inclusión en el esquema perverso del médico nazi, o, por haber declinado, como diría Primo Levi, en su "facultad de negar [el] consentimiento" ${ }^{21}$ a los vejámenes que era sometida.

Es posible coincidir con Dovi en que el estatus moral de Sophie es indeterminado, pero las razones no tienen que ver directamente con el caso específico en el que se ve involucrada, a partir del cual Dovi extrae una propuesta de método de elección; las razones, más bien, deberían buscarse en el concepto de campo expuesto por Agamben. Efectivamente, como lo mostramos al principio, el campo es un orden excepcional, es decir, un orden que se funda en la suspensión de la ley normal y que tiende a volverse permanente. $\mathrm{Y}$ es eso lo que muestra el film cuando Sophie expresa, con toda la vergüenza que eso le causa, su conocimiento, desde Cracovia, del discurso racial nazi y de los planes de exterminación de los judíos. De hecho, le cuenta a Stingo que su padre era un ferviente simpatizante del antisemitismo nazi y que ella le ayudaba a transcribir los discursos que él impartía en la universidad para buscar apoyo político a sus propuestas antijudías. De modo que, sin darse cuenta, Sophie "entró" al campo en el momento en que decidió convivir con las prerrogativas del orden excepcional que los nazis habían establecido y extendido a las zonas ocupadas. Su aceptación de este orden, así fuera por motivos de supervivencia, se evidencia en el hecho de haber atesorado una hoja con un fragmento del discurso en el que su padre sugiere la "solución final al problema judío” antes de que los nazis la formularan. Con esto en sus manos, Sophie intenta convencer a Höss acerca de que su internamiento en el campo fue un error, pues ella es una "polaca simpatizante del Nacionalsocialismo" y "militante en la guerra sagrada contra los judíos". A lo cual el comandante responde que, al ser polaca -así no haya cometido ningún crimen-, cuenta como enemiga del Reich, de modo que sería "ilegal” liberarla.

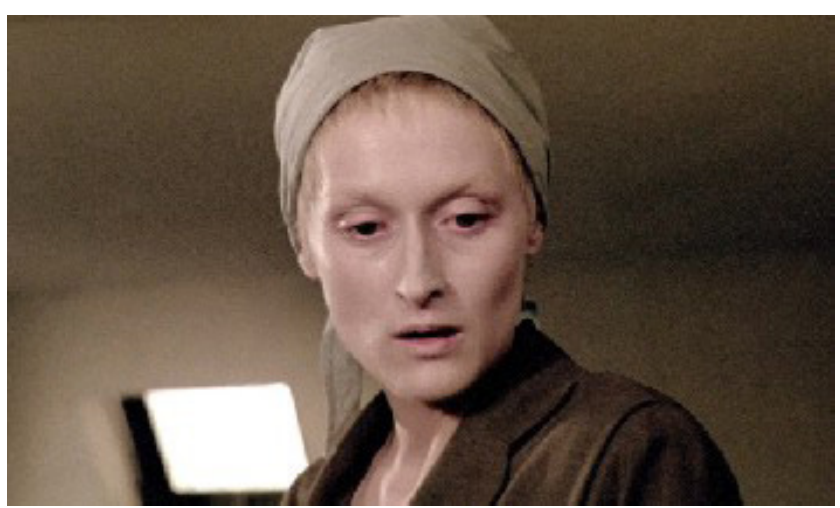


Por eso, es bastante diciente que Sophie vea en el programa Lebensborn, que de por sí es una medida totalmente ilegal desde el derecho normal, una salida legal para liberar a su hijo. Sin embargo, Sophie llegó a ser consciente de la completa perversión de lo que debía entenderse como un comportamiento éticamente correcto en los tiempos oscuros del nazismo. Precisamente, en la novela original, cuando Sophie estaba narrando su intento de convencer a Höss para que liberara a Jan, se detiene para reflexionar:

"En los campos de concentración la gente se comportaba de maneras muy diferentes: unos con cobardía y egoísmo, otros con valentía y altruismo; la conducta no era en absoluto uniforme. Era tan terrible Auschwitz... Sí, Stingo, increíblemente terrible: nunca podías decir si una persona haría cierta cosa de manera noble y honrada como hubiera podido esperarse en el mundo exterior. Si esa persona optaba por un acto de nobleza, era tan digna de admiración como si hubiese vivido en otro lugar -en realidad, más-, pero tal conducta era allí muy difícil de poner en práctica. Los nazis eran unos asesinos, y cuando no mataban a los prisioneros los convertían en animales enfermos de cuerpo y espíritu; por ello, si el comportamiento de las personas no era allí tan noble como habría sido de desear, o incluso resultaba propio de seres irracionales, había que comprenderlo, detestándolos tal vez, pero teniendo piedad por ellos al mismo tiempo, porque también tú estabas expuesto a actuar como un animal en el momento menos pensado." [...] "Sin embargo -prosiguió-, hay una cosa que sigue siendo un misterio para mí: el motivo de que me sienta tan culpable por mi conducta allí, aun sabiendo lo que acabo de decirte y que los nazis me convirtieron en un animal enfermo como a todos los demás. Y también me siento culpable de seguir con vida. Es una culpa de la cual no puedo librarme, de la que no creo poder librarme jamás... [...] Y el hecho de que no pueda deshacerme nunca de esta culpa es lo peor que me dejaron los alemanes".22

Este pasaje muestra perfectamente la indeterminación moral de todos los que se hallaban en los campos, pero, a la vez, la sensación de culpa que los embarga. ¿Por qué sucede esto? El orden excepcional del campo contempla la configuración de unas formas sociales específicas, acopladas a los mecanismos biocráticos del nazismo: normalización absoluta de la vida, doble cierre del cuerpo y supresión anticipada del nacimiento, lo cual implica que también había una especie de "ética" que aseguraba un comportamiento al servicio del cumplimiento del destino del Reich y de sus enemigos. La mayoría de quienes se encontraban en el campo se adecuaron, consciente o inconscientemente, a este modelo de comportamiento. Por esto, aquellos que tenían una posición dominante, y que eventualmente fueron juzgados, decían haber cumplido con el deber; mientras que aquellos que se encontraban en posición de dominados, los sobrevivientes, sienten culpa al comparar su manera de actuar en el campo con los estándares éticos tradicionales. A propósito, uno de los episodios más interesantes del film es en el que Höss y el médico Jemand sostienen la siguiente conversación:

[Höss y Jemand comparten una comida en el patio de la casa y se disponen a tomar vino (Sophie puede escuchar la conversación mientras come en el sótano)].

-Höss: Se ve bien.

-Jemand: Casino bebia... antes de venir aqui. ¿Se imagina? Mi padre me preguntó qué clase de medicina practico aquí. ¿Qué puedo decirle? Realizo el trabajo de Dios. Elijo quién vivirá y quién morirá. ¿No es ese el trabajo de Dios?

-Höss: Usted es demasiado joven para recordar lo que sufrió Alemania en la derrota. No podemos permitirnos ser amables si queremos sobrevivir. Hay una epidemia en el campo de los niños. No importa lo que hagamos mueren como moscas. No se puede permitir ser tan sensible.

No hay que olvidar que este es el mismo médico que obliga a Sophie a elegir y que este diálogo es cronológicamente posterior a esa escena, aunque en la película el diálogo se da antes de que se sepa lo que había ocurrido en el momento de la selección. Lo que se evidencia aquí es que aún quienes tenían posiciones de mando sentían que había una contradicción entre el comportamiento que se esperaba de ellos en el campo y sus intuiciones morales, por lo que intentaban encontrar justificaciones para sus acciones, así fuera en razones extra-morales como las divinas. De acuerdo a esto, se podría pensar que la elección hecha por Sophie sí fue una decisión ética, pues se plegó al modelo de comportamiento que exigía el nazismo, dentro del cual una de las acciones fundamentales es la decisión sobre la vida y la muerte de las personas. Pero aún resulta discutible el hecho de que se pueda encontrar responsabilidad moral en una situación en la que el dilema no se presenta a partir de las propias acciones de Sophie, sino que es un agente externo el que le presenta unas opciones que realmente conducen a un único desenlace. Además, también puede discutirse si la decisión entre la vida y la muerte de una persona da lugar, en el caso del campo, a un dilema real, pues, más que una situación en la que entran en conflicto valores 
igualmente importantes, se trata, y así se presentaba, de una decisión técnica. El destino de todos los que entraban al campo estaba decidido de antemano.

Debe concluirse, entonces, que es muy difícil hablar de una decisión ética en el campo, puesto que este es un espacio en el que las reglas son suspendidas -y las normas éticas son reglas-, para dar lugar a un orden en el que todo es posible, en el que lo que estaba limitado por las reglas deja de estarlo y lo que estaba fuera del alcance del poder ahora es su objeto principal de dominación. Sin embargo, como orden excepcional, el campo prevé, casi milimétricamente, unas formas de comportamiento específicas, un ethos particular, que no tiene nada que ver con el ethos que emerge en la acción libre de los individuos.

Para finalizar resulta pertinente retomar la frase de Giorgio Agamben que sirve de epígrafe al presente escrito: "El hecho del que debe partir todo discurso sobre la ética es que el hombre no es, ni ha de ser o realizar ninguna esencia, ninguna vocación histórica o espiritual, ningún destino biológico. Sólo por esto puede existir algo así como una ética: pues está claro que si el hombre fuese o tuviese que ser esta o aquella sustancia, este o aquel destino, no existiría experiencia ética posible, y sólo habría tareas que realizar". ${ }^{23} \mathrm{De}$ acuerdo a esto, en el campo definitivamente no se puede tomar una decisión ética, pues es un dispositivo que tiene como fin materializar las ideas sobre el destino histórico y biológico del pueblo alemán y, por contraposición, del "pueblo" judío - por no decir del resto de la humanidad.

Si se puede hablar de una decisión ética de Sophie, tendría que ser en el momento en que fue consciente de la ideología nazi y sus objetivos. Este podría ser el instante narrado más importante del film desde el punto de vista ético. Nuevamente, antes de describir su arribo al campo, Sophie le habla de su padre a Stingo y comienza diciéndole que, cuando era niña, lo admiraba mucho, pero que después, cuando creció, llegó a darse cuenta de lo mucho que lo odiaba. Por esto, le cuenta que, en el invierno de1938, ella se dedicaba a transcribir uno de los últimos discursos de su padre: "El problema judío de Polonia", cuando se encuentra con una expresión que, a pesar de que ella normalmente no se interesaba por nada de lo que se decía, le llamó la atención: "La solución para el problema judío de Polonia es la Exterminación”. El impacto que le causó esta expresión la impulsó a ir al gueto judío en Cracovia, pues quería observar a la gente que su padre había "condenado a morir". ${ }^{24}$ Debido a este desvío, Sophie se atrasó en su trabajo y cometió errores de transcripción. Su padre leyó el discurso con los errores, por lo cual se puso furioso con Sophie y la increpó. Sophie cuenta que quiso decirle a su padre que era horrible lo que pretendía hacerles a los judíos -cuestionarlo por su posición, pero que no tuvo el valor para hacerlo.

Claramente Sophie tuvo una vivencia singular: la experiencia de cercanía con unas personas que le eran totalmente ajenas; de aquí ella pudo intuir que no existía ninguna razón para hacerles daño y que merecían tanto respeto como cualquier otro. A partir de esta experiencia, Sophie estaba dispuesta a cambiar su vida -que para el caso de ella se resume en tomar distancia de las ideas de su padre-, pero el temor la embargó y no pudo distanciarse de las concepciones antisemitas de su padre y de un entorno que veía a los nazis como el modelo a seguir. Es aquí donde realmente se puede hablar de una decisión ética de Sophie, pues se abrió para ella una visión propia acerca de lo que las personas del gueto eran y de lo que merecían, dejándola ante la posibilidad de vivir de acuerdo a esta visión (pase lo que pase) o de negarse a vivir y simplemente seguir la corriente. Fue en este momento cuando Sophie pudo decidir y no lo hizo. De ahí en adelante lo único que podía pasar era que se cumpliera su destino, el cual venía dado por su padre y su esposo, pero que, en adelante, sería dado por los nazis y por las diatribas del campo de concentración.

\section{Referencias}

Agamben, G. (2006). La comunidad que viene. Trad. José Luis Villacañas, Claudio La Rocca y Ester Quirós. Valencia: Pre-Textos. Agamben, G. (2010). Medios sin fin. Notas sobre política. Trad. Antonio Gimeno Cuspinera. Valencia: Pre-Textos.

Dovi, S. L. (2006). Sophie's choice: letting chance decide. Philosophy and Literature, 30(1), 174-189.

Esposito, R. (2006). Bíos. Biopolítica y filosofía. Trad. Carlo R. MolinariMarotto. Buenos Aires: Amorrortu.

Pakula, A. (productor y director) (1982). Sophie'schoice [cinta cinematográfica]. EE.UU.: Universal Pictures.

Styron, W. (1980). Sophie. Trad. Antoni Pigrau. Barcelona: Grijalbo.

Tendlarz, S. E. (2013). Shoa. Ética y Cine Journal, 3(2), 83-88. 
Agamben, G. (2010). Medios sin fin. Notas sobre politica. Trad. Antonio Gimeno Cuspinera. Valencia: Pre-Textos, p. 37.

2 Nótese que, en este punto, cuando hablo de "vida" me refiero a la vida biográfica, a las aspiraciones o expectativas que cada quien tiene con respecto a lo que puede y quiere ser como persona socialmente reconocida.

$$
\begin{aligned}
& \text { Agamben, 2010, p. } 38 \\
& \text { Ibíd., p. } 39 . \\
& \text { Ibíd., pp. 40-41. }
\end{aligned}
$$

6 La expresión "totalidad de la sociedad" no hace referencia únicamente a todos lo que se consideran miembros de la sociedad, sino también a todos los aspectos de la vida social, incluyendo los biológicos.

Véase: Esposito, R. (2006). Bíos. Biopolítica y filosofía. Trad. Carlo R. MolinariMarotto. Buenos Aires: Amorrortu, p. 179.

$8 \quad$ Véase: Ibíd., pp. 228-229.

9 Véase: Ibíd., pp. 233-234.

10 Aunque en la novela de Styron se revela que inicialmente la atraparon porque sospecharon que era miembro de la resistencia. Véase: Styron, W. (1980). Sophie. Trad. Antoni Pigrau. Barcelona: Grijalbo, p. 170.

11 En la novela, Styron, en voz de Sophie, explica que Auschwitz era realmente dos campos, uno al que eran enviados quienes podían realizar trabajos de toda índole y otro (Birkenau) al que eran enviados quienes debían ser exterminados. (Véase: Styron, 1980, Ibíd.)

12 Styron revela que el nombre de este personaje es Fritz Jemand. (Véase: Styron, 1980, p. 561.)

13 Es importante saber cómo narra Styron la secuencia, pues, según el escrito, durante la espera de Sophie y sus hijos en el vagón se vivieron momentos realmente angustiosos, particularmente cuando llegaron noticias sobre el envío de todos los judíos y los miembros de la resistencia a cámaras de gas. Lo siguiente que recordó Sophie fue el hecho de encontrarse con los dos niños en el andén y el posterior episodio con el médico Hauptsturmführer Fritz Jemand. Este hombre tenía unos 35 a 40 años y era bien parecido, pero cuando se dirigió a Sophie por primera vez le insinuó toscamente querer llevarla a la cama, lo cual parecía explicable por el hecho de estar visiblemente borracho. Posteriormente, el doctor le dijo que sabía que ella era polaca y le preguntó si también era comunista, a lo cual Sophie no respondió. Cuando parecía perder la atención, Sophie se arriesgó y le dijo, en perfecto alemán, que efectivamente era polaca, de Cracovia, que ni ella ni los niños eran judíos, que hablaban perfectamente alemán y que era cristiana-católica. Con esto llamó de nuevo la atención del doctor, quien le dijo: "¿Así que crees en Cristo el Redentor? [...] ¿No dijo Él: 'Dejad que los niños se acerquen a mí'? [...] Pues puedes quedarte con una de las criaturas." “-¿Cómo? -dijo Sophie. -Que puedes quedarte con una de las criaturas -repitió-. La otra tendrá que irse. ¿Con cuál te quedas?

$-¿$ Quiere decir que tengo que escogerla?

-Tú eres polaca y no judía. Eso te da un privilegio, una opción. Las facultades pensantes de Sophie disminuyeron, cesaron. En- tonces tuvo la sensación de que las piernas no le aguataban. - ¡No puedo elegir! ¡No puedo elegir! -empezó a gritar. ¡Cómo recordaba sus propios gritos, después de tanto tiempo!-. Ichkannnichtwählen! -repitió a gritos. El doctor advirtió que a su alrededor se le estaba prestando más atención de la que deseaba. -¡Cállate! -le ordenó-. Y ahora a escoger en seguida. Escoge de una vez, si no los envío a los dos allí. ¡Deprisa! Sophie no podía creer lo que estaba sucediendo. [...] Su incredulidad era total, insensata. Y reflejaron también incredulidad los ojos del flaco y joven Rottenführer, el cabo de primera ayudante del doctor, a quien se encontró mirando con expresión suplicante. El hombre parecía sorprendido y le devolvió la mirada con unos ojos abiertos de par en par que parecían decir: "No, no lo entiendo". -No me haga elegir -susurró ella-. No puedo elegir.

-Bueno, pues mándelos a los dos a la izquierda -dijo el doctor al ayudante-, nach links, sí, hacia la izquierda.

-¡Mamá! -oyó Sophie que decía su hija, con un grito delgado pero estremecedor, en el instante en que ella la levantó de la superficie del hormigón con un torpe y vacilante movimiento. -¡Tome a la niña! -gritó-. ¡Quédese con mi hijita! En aquel momento el ayudante, con una delicadeza que Sophie habría querido olvidar, pero que recordaría siempre, tiró de la mano de Eva y la condujo hasta la legión de condenados." (Véase: Styron, 1980, pp. 560-564).

14 Véase: Dovi, S. L. (2006). Sophie's choice: letting chance decide. Philosophy and Literature, 30(1), p. 176.

15 Dovi, 2006, p. 175. (Todas las traducciones del inglés son mías).

16 Ibíd.

17 Véase: Dovi, 2006, pp. 177-178.

18 Véase: Ibíd., pp. 183-184.

19 Con respecto al programa Lebensborn, Styron dice en la novela, en voz de Stingo: "Una de las operaciones más siniestras y menos conocidas de los planes nazis fue el programa llamado Lebensborn. Producto del delirio filogenético de los nazis, el Lebensborn (literalmente, fuente de vida) fue proyectado para aumentar las filas del Orden Nuevo, al principio mediante la sistematización de un programa educativo y, después, gracias al rapto organizado, en las zonas ocupadas, de niños racialmente "idóneos" que eran enviados al interior de su tierra natal para que residieran en hogares fieles al Führer, con lo que se esperaba que se criasen en una atmósfera asépticamente nacionalsocialista. Teóricamente, esas criaturas tenían que constituir la más pura progenie alemana”. (Styron, 1980, p. 352.)

20 Dovi, 2006, pp. 179-180.

21 Citado por Tendlarz, S. E. (2013). Shoa. Ética y Cine Journal, 3(2), p. 85.

22 Styron, 1980, pp. 335-336. ${ }^{23}$ Agamben, G. (2006). La comunidad que viene. Trad. José Luis Villacañas, Claudio La Rocca y Ester Quirós. Valencia: Pre-Textos, p. 41.

24 Se trata de una imagen en la que Sophie está de pie en la mitad de una de las calles del gueto viendo la gente pasar, sin que pueda encontrar una diferencia entre ella y los transeúntes, y si sentir ningún tipo de resentimiento hacia aquellas personas; se puede decir que Sophie prácticamente se camufla en el paisaje. 